\title{
Escola de homens de ciências: a Academia Científica do Rio de Janeiro, 1772-1779
}

\section{School of science men: the Scientific Academy of Rio de Janeiro, 1772-1779}

\author{
Vera Regina Beltrão Marques*
}

\begin{abstract}
RESUMO
O presente trabalho trata da Academia Científica do Rio de Janeiro como escola na qual formavam-se homens de ciências. Espaço de ensino e aprendizagem, caracterizava-se como um local no qual se observava a natureza, fazia-se experimentos, debatia-se achados, socializava-se informações e reflexões políticas, oportunizando formação teórico-prática aos seus partícipes. Funcionando como associação ligada ao vice-reinado, extrapolava o papel de subsidiar o Reino em temas atinentes à melhor exploração econômica da colônia, desempenhando também funções de cunho educativo ao possibilitar a circulação de uma cultura científica via aprendizado das ciências da natureza, denotando a chegada da ilustração em terras brasílicas.

Palavras-chave: escolas de ciência, academias setecentistas, natureza brasílica.
\end{abstract}

\begin{abstract}
This work focuses Scientific Academy of Rio de Janeiro as a school that graduated men of science. That was a teaching and learning place characterized by practices of nature observation, experiment making, discovering debate, information socialization and political thought, which gave opportunity of theoretic and practical formation to its participants. Working as an association linked to the Vice-Kingdom, the Academy
\end{abstract}

* Doutora em história (Unicamp). Professora do Departamento de Teoria e Fundamentos da Educação da Universidade Federal do Paraná - UFPR. E-mail: verarbm@terra.com.br 
extrapolated the role of producer of information related to the best economic exploration of the colony and developed functions of educative nature in a way it enabled circulation of a scientific culture related to natural sciences, denoting illustration arriving to Brazilian land.

Key-words: Science school, XVII Century Academies, Brazilian nature.

\section{Em tempos de academias}

O ensino ilustrado da história natural caminhou ao passo com criação de academias científicas em vários países europeus. Tornara-se fundamental investigar cientificamente a flora ultramarina das colônias em fins do século XVII. E a ciência em muito vinha contribuir. "É o século de Galileu, de Descartes, de Huygens, de Leibniz, de Boyle, de Hooke, de Fermat, e de tantos outros, que dão à ciência uma dimensão social que até aí não tivera. Começa a entender-se a investigação científica como motor de progresso material" (CARVALHO, 1981, p. 10) oferecendo novas formas de apropriar-se da natureza, especialmente nas colônias mais pródigas.

Várias academias científicas foram criadas com tais objetivos, ainda no Seiscentos. Vale destacar: Collegium Naturae Curiosum, em Schweinfurt, na Alemanha (1651); Accademia del Cimento, em Florença (1657); Royal Society, em Londres (1660); Académie des Sciences, em Paris (1666). Em suas sessões liam-se os trabalhos produzidos pelos cientistas; em seguida debatiam-se exaustivamente os temas apresentados, após o que publicavam-se essas memórias em periódicos como, por exemplo, no Philosophical Transactions (Royal Society) ou no Journal de Savants (Académie des Sciences). Essas academias eram "congregações do saber" e nelas encontravam-se os homens notáveis prontos a auxiliarem os governos em questões de ciência e técnica, assim como na economia, meteorologia, solos, climas, faunas, floras, etc (CARVALHO, 1981, p. 11).

Em Portugal, expandia-se gradativamente o interesse pelas ciências da natureza e a Academia das Ciências de Lisboa seria fundada no Setecentos ao realizar sua primeira reunião em 16 de janeiro de 1780 , sob a presidência do duque de Lafões, título obtido por D. João Carlos de Bragança, em seu retorno a Portugal, após a morte de D. José I.

A instituição viera na expectativa de mudar o quadro bastante debatido por intelectuais portugueses, a exemplo de Antônio Ribeiro Sanches e Luís 
Antônio Verney: ultrapassara-se a fase do "dar a ver", do revelar a natureza criada por Deus. Os novos ventos científicos sopravam na direção da secularização da ciência; da emancipação da tutela da teologia e da metafísica. A Academia Real das Ciências de Lisboa (ARCL) se propunha a realizar um movimento intelectual que promovesse o Estado e sua economia, além de instruir o povo e assim retirar os portugueses de um isolamento filosófico, pedagógico e científico de muito tempo (MUNTEAL FILHO, 1993, p. 183-184). Sob as hostes do reinado de D. Maria I, pretendeu-se fazer de Portugal um estado moderno, ao passo com o desenvolvimento científico de outras nações européias. ${ }^{1}$ A fundação da ARCL, juntamente com a reforma da Universidade de Coimbra, indicavam o quanto o novo reinado abraçara as idéias ilustradas, tendo na sociabilidade disseminada por essas instituições pedra de toque para a difusão da ilustração em Portugal e no investimento em políticas de fomento.

Correia da Serra, naturalista português, formado na Itália e um dos mais conceituados fundadores da Academia de Ciências de Lisboa, assim define a importância da história natural e sua utilidade na exploração dos domínios portugueses:

O primeiro passo de uma nação, para aproveitar suas vantagens, é conhecer perfeitamente as terras que habita, o que em si encerram, o que de si produzem, o de que são capazes. A história natural é a ciência que tais luzes pode dar (...). Dar-nos a conhecer o que temos; ensinar-nos a aproveitá-lo; escolher no sistema de variedade das produções da natureza, espalhados por outras terras, novas plantas, animais, e culturas análogas aos climas, e terrenos que os portugueses habitam (1789, p. III).

As idéias sobre a importância dos estudos sobre a natureza haviam, de fato, chegado a Portugal e vinham endossar o que filósofos naturais e sábios

\footnotetext{
${ }^{1}$ Embora considerado por muito tempo como "volta ao obscurantismo", o reinado de D. Maria manteve parte da administração após 1777 como bem demonstra a historiografia atual. O secretário da Marinha e Ultramar, Martinho de Melo e Castro, por exemplo, permaneceu mantendo os princípios fundamentais da política para a área. No que concerne à educação, estendeu-se consideravelmente o número de professores régios de leitura e escrita, ampliando a instrução. No que concerne as vicissitudes dessa ampliação ver: Carlota Boto em "Iluminismo e educação em Portugal", p. 169-191.
} 
do Seiscentos já encontravam-se de acordo: "a Natureza é uma máquina e a ciência é a técnica de exploração desta máquina” (LENOBLE, s.d., p. 262).

Até então, em terras do Brasil, as academias abertas tiveram duração exígua e seus trabalhos cunho literário. A Academia Brasílica dos Esquecidos (1724) manteve-se por 18 sessões, tendo sócios seletos e preocupação distinta, pois foi criada na expectativa de reunir documentos para auxiliar os trabalhos da Academia Real de História Portuguesa, criada por D. João V. Dissertações foram produzidas, contemplando "diferentes aspectos da história do Brasil. Além disso estimulou Sebastião Rocha Pita a concluir sua História da América Portuguesa (1730)" (VAINFAs, 2000, p. 14)²

Em meados do Setecentos, o empenho preponderante da metrópole ainda recaia na exploração dos recursos naturais centrado nos metais e pedras preciosas, empenho esse que recebia severas críticas. José Henriques Ferreira, filósofo e médico do vice-rei marquês de Lavradio, primeiro médico do Hospital Real e um dos mais destacados fundadores da Academia Científica ou Academia de Medicina e História Natural do Rio de Janeiro, assim se manifestava em relação às riquezas naturais do Brasil:

As preocupações da natureza e da arte ou são de primeira necessidade e estas são as que nos sustentam, nutrem, curam das doenças e vestem, ou da segunda; que nos servem de lucro, divertimento, deleite. De ambas produzem o Brasil com liberalidade se bem que as de primeira necessidade estão esquecidas; e perdidas porque a cobiça arrasa a pós, [sic] das outras os seus habitadores. Cuida-se porventura na agricultura daquele país? Não, o ouro e os diamantes são os atrativos dos seus habitadores, e os despovoadores da gente africana. Seria mais útil, que esta gente empregada em desentranhar a força do trabalho da terra, o ouro e os diamantes se ocupasse na cultivação das terras. Que utilidade não tiraríamos da cultura do arroz, dos trigos, dos milhos e de toda a sorte de grãos que ali a natureza sem trabalho produz? Não podemos escusar as manteigas, queijos que as outras nações nos vendem, se ali se promovem estas matérias? A pescaria naquele país estabelecida nos pode subministrar o peixe necessário e escusar-nos o bacalhau de fora, e ali também temos este. (ACL, Manuscrito azul n. 374, fl.341v-342).

${ }^{2}$ Nizza da Silva (1994) no verbete Academias explica que a Academia dos Esquecidos ao se propor a escrever a História brasílica pretendeu dividi-la em quatro partes: História Natural, História Militar, História Eclesiástica e História Política. Para discussão acerca da natureza brasílica e sua abordagem até a criação da Academia Científica ver Vera Regina Beltrão Marques: Natureza em boiões, cap. 1-2. 
Alertava para os riscos que corriam os países que privilegiavam a extração de metais nobres e pedras preciosas sem dar a devida atenção à agricultura. Nesse manuscrito, Henriques Ferreira diz ter enviado para a Corte uma relação de várias produções naturais que são úteis na medicina e no comércio e que não relegariam a um segundo plano a pródiga flora medicinal brasílica e a possibilidade de desenvolvimento agrícola.

\begin{abstract}
A jalapa sobre a qual meu irmão Manoel Joaquim Henriques de Paiva leu na Academia uma dissertação e uma resposta apologética. $\mathrm{O}$ mexoacão legítimo que em Portugal se compra e falsamente usa por ele pela ignorância da maior parte dos boticários, a raiz de norça negra como na mesma Academia demonstrou meu pai Antônio Ribeiro de Paiva. A salsaparrilha do Maranhão e Honduras, a resina Elemi, a goma Anime, a de peixe, o incenso, a canafístula, o archiote tinta excelente. A goma de cajú, a raiz da China, os tamarindos, o azougue e vários purgantes benignos e outros drásticos de que há abundância, assim como de outros gêneros que estamos comprando e não tive resposta nem determinação alguma sobre isto (ACL, Manuscrito azul n. 374, fl. 345).
\end{abstract}

Ferreira não era o único cientista no século XVIII colonial com esta preocupação, e seus registros denotam o pensamento de uma geração de ilustrados que começara a se formar, cujas atenções à natureza estimulavam ações oficiais da Coroa. A chegada em Portugal de Domenico Vandelli em 1764, especialmente contratado pelo marquês de Pombal para participar da ampla reforma educacional que se intentou após a expulsão dos jesuítas, trouxera os estudos de história natural para a "ordem do dia". Assim, caixotes e mais caixotes atravessaram o Atlântico levando exemplares da flora e fauna das colônias para comporem os jardins botânicos que se instituíam. O empenho do marquês de Lavradio, ao apoiar a criação da Academia no Rio de Janeiro, cabia nos objetivos de Pombal em incentivar os estudos de história natural. Logo a criação da Academia Científica foi fruto desse espírito científico empreendedor de vários homens sintonizados com os princípios do movimento das Luzes. 


\section{Escola de ciências em solo pátrio}

É emblemática a fundação, sob os auspícios do vice-rei, marquês do Lavradio, da Academia das Ciências e da História Natural do Rio de Janeiro, ligada à Academia Real das Ciências da Suécia. Sua primeira reunião realizou-se em 18 de fevereiro de 1772, alguns anos antes da criação da Academia das Ciências de Lisboa. Nessa sessão foram eleitos presidente e secretário: José Henriques Ferreira e o cirurgião Luís Borges Salgado, respectivamente (VARNHAGEN, 1962, t. 4, p. 265) e seus primeiros sócios foram: Gonçalo José Muzzi e Antônio Freire Ribeiro (médicos); Maurício da Costa, Idelfonso José da Costa Abreu, Antônio Mestre e Luiz Borges Salgado (cirurgiões); Antônio Ribeiro Paiva e Manoel Joaquim Henriques de Paiva (boticários) e o curioso de agricultura, Antônio José Castrioto. (o PATRIOTA, 1814, p. 3).

O boticário Antonio Ribeiro de Paiva, diretor de História Natural na Academia e pai de Henriques Ferreira, falou na solenidade de abertura sobre "todos os ramos desta vastíssima ciência, e em particular sobre o da Botânica, e do proveito que no Brasil se podia tirar de sua cultura" (O PATRIOTA, 1814, p. 5).

A Academia de Medicina e História Natural tratava das ciências naturais e as sessões ocorriam às quintas-feiras na sede da Academia e, aos sábados, no posto botânico que fora criado próximo ao antigo Colégio dos Jesuítas. Nessas reuniões eram "apresentadas dissertações eruditas, as notícias de várias descobertas que interessavam ao estudo da História Natural e propostos alvitres para o progresso da agricultura, indústria e comércio" (O PATRIOTA, 1814, p. 5). O empenho de seus membros na busca de uma atualização e circulação constante de conhecimentos ensejava trocas de correspondências, como a de José Henriques Ferreira, fundador da Academia, com Antonio Nunes Ribeiro Sanches, ${ }^{3}$ assinalada em uma memória sobre a cochonilha: "Transcreverei para aqui alguns capítulos de uma carta que me escreveu de Paris o Dr. Antonio Ribeiro Sanches em resposta de outra em que lhe dava notícia da Academia que aqui tinha procurado estabelecer, e de outras matérias e produções deste país" (ACL, Manuscrito azul, n. 374, f. 343v). Ribeiro Sanches trocava cartas também com o irmão de Henriques Ferreira, Manuel Joaquim Henriques de Paiva, que viera para o Brasil com seu pai, o boticário Antonio Ribeiro de Paiva, em 1769 (Lemos, 1911). Correspondências que muito vi-

3 Ribeiro Sanches era médico, discípulo de Boerhaave em Leyde, depois se dirigiu para a Rússia onde se distinguiu como médico e administrador. Suas idéias tiveram repercussão na reforma da Universidade de Coimbra em 1772. 
nham contribuir em apoio e subsídios aos empreendimentos da Academia, pois Antônio Ribeiro Sanches tornara-se um dos grandes inspiradores do iluminismo português, mesmo que a distância, pois na qualidade de filho de cristãos-novos optara por não voltar a Portugal após sua formação.

O contato de Ribeiro Sanches com os Henriques de Paiva resultava em propostas avançadas de história natural, dentre elas, possivelmente a idéia de criar a própria academia, endossadas pelo também ilustrado vice-rei marquês de Lavradio. Com conhecimentos e interesse na matéria, sabia que sua política de fomento não se sustentaria sem uma sociedade científica (WEHLING, 1977, p. 240). O que pode ser constatado nas palavras do vice-rei:

por efeito das admiráveis plantas, e raízes, óleos, bálsamos e gomas de que é cheio todo este Continente, no qual a maior parte são desconhecidos, e alguns que já se conhecem se não têm comunicado a mais parte alguma e a estes lhe dão usos muito impróprios dos que deviam ter, deixando por esta causa de se aproveitar mais este ramo de comércio, e termos mais aquele socorro para a nossa duração, resolvi-me a fazer um ajuntamento de médicos, cirurgiões, botânicos, farmacêuticos, e alguns curiosos, assim desta capital, como dos sertões desta Capitania, formando com eles uma assembléia, ou academia para se examinarem todas a cousas que se puderem encontrar neste Continente pertencente aos 3 reinos: vegetal, animal, e mineral, fazendo-lhes todas a análises, e mais observações que couberem no possível, para ir dando ao público em todos os meses, uma completa notícia dos descobertos que se forem fazendo, parecendo-me que deste modo poderei conseguir fazer ao estado e à Pátria, não só um serviço utilíssimo mas até concorrer para que não continuemos a passar pela vergonha de que os estrangeiros sejam só $o(s)$ que nos instruam, e se aproveitem destas preciosidades que nós temos, mas que nós possamos ser os que os instruamos a eles, e tiremos as grandíssimas utilidades que daqui nos podem resultar (LAVRADIO, 1772/1978, p. 97).

Porém Ribeiro Sanches bem compreendia de onde provinha o projeto de

haver-se formado essa Academia por insinuação de vmce. e estabelecerse pela inteligente proteção do Exmo. Sr. Marquês do Lavradio, acho de 
maior conseqüência para a utilidade do comércio do Reino, se em Lisboa quiserem entrar no gênio das nações que pensam a sua conservação e aumento, do que até agora estamos muito atrasados. Os castelhanos que não têm os olhos mais perspicazes que nós souberam fazer dos produtos da História natural da sua América negócio de muito rendimento para eles e de muita utilidade para a Europa. Tiveram a habilidade de fazer entrar no comércio a cochonilha, a quina, a jalapa, a contra-erva, os bálsamos, a cevadilha, (...). Nós tão desasados desde duzentos anos não tivemos habilidade de fazer entrar no comércio a raiz de mil homens, a casca barbatimão, a almeçaga e outras mil raízes, frutos e cascas que podem servir na medicina e nas artes tintas. E admiro-me como o óleo de copaíba e a ipecacuanha chegaram a ser conhecidas devemos aos quondam jesuítas (ACL, Manuscrito azul, n. 374, fl. 342-343).

Ribeiro Sanches aludia a necessidade de explorar racionalmente a natureza do Brasil, destacando produtos capazes de gerar riquezas comerciais que se explorados, reverteriam em muita utilidade, possibilitando ao Reino "entrar no gênio das nações".

Prosseguia a elencar outros produtos das colônias africanas, também não cultivados e, censurando a falta de empenho em conhecer os remédios naturais usados pelos nativos; acrescenta que "sem fazer avanços e sem gastar jamais haverá, nem ciências, nem artes, nem comércio, nem estado civil". Foi também por meio de Sanches que Lineu teve notícias da fundação da Academia Científica do Rio de Janeiro, oportunizando-lhe discussões acerca dos achados neste lado do Atlântico.

Sanches referia-se também ao Brasil na memória intitulada Considerações sobre o governo do Brasil desde o seu estabelecimento até o presente tempo (1777), na qual abordava o descaso com que Portugal tratava a agricultura e a indústria nesta parte do Reino, ocupando-se somente do "ouro e da prata que foram alimentar indústrias de outros países". Na sua ótica, no Brasil não se deveriam estabelecer "monopólios, privilégios, contrato de tabaco, companhias, estanques (estancos), dízimos eclesiásticos, bens de raiz eclesiásticos", contrariando, portanto, a forma de gerência colonial existente (LEMOS, 1911, p. 187). Essas idéias geravam discussões nas correspondências trocadas entre Sanches e os acadêmicos, que assim estabeleciam elos para além do controle metropolitano, ampliando a interlocução de idéias e conhecimentos em circulação. Logo a ilustração professada por um dos grandes inspiradores do iluminismo português chegava em terras brasílicas sem censura, nem intermediação metropolitana, apontando para uma das razões que 
podem ter contribuído para fundar-se em terras coloniais a primeira academia de ciências portuguesa. Ademais a filiação da Academia Científica à Academia de Ciências da Suécia, terra de Lineu, não se dera por acaso e certamente Ribeiro Sanches teve participação nesta filiação.

\section{Práticas científico-pedagógicas}

Da Academia partiam duras críticas concernentes ao desenvolvimento da história natural no Reino e às dificuldades enfrentadas pelos acadêmicos. Essas críticas eram procedentes a se considerar: boticários, cirurgiões e médicos mantinham estreitas ligações com a natureza. Dela provinham as plantas que curavam e dali se retiravam os medicamentos aplacadores das doenças do corpo. "A urgência de encontrar nome para as doenças, a necessidade de identificar as propriedades curativas dos medicamentos, o imperativo de perceber como é que a natureza pode auxiliar o bom funcionamento da saúde supõe um olhar atento e prevenido, ou seja o ver" (JANEIRA, 1991, p. 19). Logo não foi por acaso que os primeiros sócios da agremiação foram boticários, cirurgiões e médicos e que buscaram nestas academias "espaços propícios a saberes norteados, não pela capacidade especulativa de cada um, como acontecia com os antigos, mas nas potencialidades da razão e das forças naturais, como é próprio dos modernos" (JANEIRA, 1991, p. 19).

O boticário Antonio Ribeiro de Paiva, desde o discurso de inaugural, proclamava a ignorância botânica da metrópole, denunciava a falta e imperícia de mestres e a dificuldade em se adquirir livros sobre a matéria. Os poucos existentes eram em latim, idioma pouco dominado pelos praticantes do ofício e pelos iniciantes no aprendizado de decifrar e lidar com a natureza. $\mathrm{O}$ atraso português nas atividades farmacêuticas também era assinalado pela ausência de ensino e prática deficiente, pelo diretor de farmácia, Manoel Joaquim Henriques de Paiva, então responsável por essa área.

Porém os acadêmicos no Rio de Janeiro colocavam-se firmes no propósito de incrementar os estudos botânicos, e por meio deles, a medicina, a farmácia e a agricultura. No próprio Estatuto da Academia fizeram constar instruções de como se proceder no tratamento das espécies. E, em relação àqueles nomeados de outras terras como Bahia, Minas, Colônia, Santa Catarina etc., determinava a obrigação de "comunicar as notícias e observações notá- 
veis do país, remetendo plantas, pedras, animais, excrescências, fungos, sementes e todas as cousas pertencentes aos três reinos, declarando os nomes, virtudes, sítios e descrevendo-as com todas as propriedades, e podendo remeter algumas plantas em cascões com terra" (CARVALHO, 1939, p. 8)

Também recebiam a incumbência de responderem às censuras e pareceres que se lhes pedissem nas dúvidas que por ventura ocorressem nas memórias apresentadas. Um deles estava encarregado de "adquirir notícias dos autores antigos e modernos" relacionados às matérias tratadas, devendo saber latim, espanhol, francês, italiano, inglês e ser "professor ou curioso de algumas das belas letras" (CARVAlHo, 1939, p. 8). A memória intitulada "História dos reinos vegetal, animal e mineral do Brasil, pertencente à medicina" de autoria do médico Francisco Antônio Sampaio (1969), do Hospital de São João de Deus da Vila da Cachoeira, apesar de ter ficado pronta somente em 1782 , constituiu certamente seu esforço em caracterizar a flora da Bahia, atendendo às solicitações da academia brasílica.

A existência do horto botânico garantia o espaço para ações práticas, constituindo espaços de aprender e ensinar ao proporcionar aos seus sócios e correspondentes, discussões de temas e práticas científicas, funcionando como local no qual ocorrem as experimentações.

Terá a Academia um horto botânico para nele se tratarem, e recolherem todas as plantas notáveis, e terá cada acadêmico obrigação de o ir ver para observar a diferença e crescimento delas. Haverá alguns coletores, os quais serão encarregados do horto botânico: haverá também alguns acadêmicos desenhadores de plantas (apud CARVALHO, 1939, p. 8).

As experiências feitas com a cochonilha relatadas por Henriques Ferreira mostram que nesse horto eram semeadas as espécies vindas de "outros terrenos", como a cochonilha ${ }^{4}$ encontrada na Ilha de Santa Catarina e transportada em caixões para o Rio de Janeiro. Maurício da Costa, cirurgião-mor do I Regimento da Praça do Rio de Janeiro, viria a conhecer a cochonilha, quando da demarcação das Américas portuguesa e espanhola, durante o governo de

${ }^{4}$ A cochonilha, o anil e o linho encontravam-se valorizados na época, pois eram empregados como matéria prima para a indústria. Pombal buscava o desenvolvimento destas culturas para obtê-las por menor custo, substituiu importações e abriu outras possibilidades de consumo. Ver Arno Wehling, 1977, p. 238. 
Gomes Freire de Andrade, o Conde de Bobadela. Achava-se o médico no "continente do Rio Grande de São Pedro", em companhia de um castelhano que, reconhecendo a cochonilha, lhe mostrou. Após buscas incessantes, encontrou-se cochonilha também no Rio de Janeiro e Bahia, tendo o vice-rei enviado exemplares para a Corte. Tentavam classificá-la, quando após estudos comparados Henriques Ferreira concluíra pela inserção da cochonilha em uma ordem diferente daquela na qual Lineu a classificara (ACL, Manuscrito azul, n. 374, fl. 320-339). Esses debates demonstram o caráter científico das reuniões enquanto um espaço no qual se estudava, ensinava e aprendia ciência, anteriormente à fundação de Academia das Ciências de Lisboa, marco dos estudos de ciência na metrópole.

No relatório entregue ao seu sucessor, Luís de Vasconcellos e Sousa, o marquês menciona o interesse pela plantação das mudas do arbusto que alimentava a cochonilha e que garantiriam seu desenvolvimento dizendo: "conservei do mesmo arbusto bastantes [sic] pés em um horto botânico que aqui estabeleci, e de que se acha encarregado, e com inspeção dele Joaquim José Henriques de Paiva [sic], para dali se poderem ir tirando plantas, e se darem a diferentes pessoas; (...)" (LAVRAdio, 1863, p. 474).

As investidas do marquês realizavam-se em perfeita sintonia com o ideário dos acadêmicos e com as necessidades do Reino (MAXwell, 1996). Prova disto são as memórias acadêmicas, posteriormente publicadas seja na própria Academia de Ciências de Lisboa, seja no jornal "O Patriota". Assim as Memórias de História Natural, de agricultura, artes e medicina, lidas na Academia Real das Ciências de Lisboa, por Manoel Joaquim Henriques de Paiva, quando de sua volta ao reino e ali publicadas no ano de 1790, tratam de várias plantas referindo-se, principalmente, àquelas que estudou no Brasil: a jalapa, a fava purgativa ou feijão peruviano- chamado também mucuná, e a guaxima, ${ }^{5}$ estudada pelo irmão, mas com classificação de gênero e espécie, realizada por Henriques de Paiva (PAIVA, 1790, p. 54).

O mucuná descrito como um gênero novo ganhou a designação de Lavradio, ${ }^{6}$ em homenagem ao vice-rei, como afirmará Paiva ao ler o trabalho na Academia de Lisboa,

5 O Marquês de Lavradio juntamente com José Henriques Ferreira e João Hopman (empresário holandês) tentavam substituir o linho de Riga pela guaxima, conforme Wehling, op. cit., p. 241. Hopman fora designado por Lavradio como "inspetor de novas plantações e fazendas" para promover culturas que ainda não faziam parte da agenda de produtos exportáveis para a Metrópole. Consultar Maxwell, 1996, p. 133.

${ }^{6}$ A descrição do mucuná, designada Lavradio, pode também ser consultada em manuscrito: ACL, Manuscrito azul, n. 324. 
em memória do Exmo, Marquês de Lavradio, criador de uma Academia de Ciências, que viu florescer de baixo do seu patrocínio, e fez dar em breve tempo passos agigantados, franqueando aos sócios, em cujo número entrava eu, para nele trabalhar, um jardim botânico, gente e instrumentos; honrando-nos, e animando muito os nossos estudos (...). Não é este um remédio recomendado, e usado somente pelos bárbaros do Brasil, e da Guiana mas já também pelos médicos e cirurgiões estabelecidos neste país, que o têm feito conhecer à Europa. (...) As sementes em pó ou botadas de molho em vinho, e água purgam por cima, e por baixo, e delas usam os caboclos do Brasil, e os negros em muitas enfermidades, quando intentam vomitar, ou purgar. A penugem que cobre a base, e a que vulgarmente chamam pós da Índia, misturada com qualquer xarope em forma de electuário é de comprovada eficácia para destruir e matar as lombrigas ... (PAIVA, 1790, p. 54).

Quanto à jalapa ou "batata de purga, segundo os naturais", após muitas observações e dúvidas pediu auxílio aos médicos e cirurgiões do Brasil, e particularmente aos membros da academia brasílica, para que observassem os efeitos de três raízes encontradas. Dos resultados das observações e análises químicas realizadas, apresentou um "Discurso analítico na sessão de 6 de abril de 1772". Discutida e aprovada a memória, comunicou-a aos boticários da cidade do Rio de Janeiro e muitos do Reino, que não acreditavam existir uma jalapa brasileira. A conhecida até então era proveniente do México. Após mais estudos, provas e aval da Academia Científica, descobriu o médico, "que já aos jesuítas era isto conhecido; pois que a cultivavam e vendiam ocultamente a sua raiz, e resina debaixo do nome de jalapa do México, do que facilmente me persuadi, porque em todas as suas possessões, e ainda mesmo na sua cerca do Rio de Janeiro se acham em abundância estas plantas" (PAIVA, 1790 , p. 50).

Importava-se a jalapa "dos espanhóis", como a "verdadeira", caro leitor, quando existia jalapa no Brasil tendo sido já explorada pelos jesuítas. $\mathrm{O}$ médico-naturalista dizia ser necessário valorizar as próprias riquezas e atentar para o que diziam homens como Lineu: "Se os portugueses conhecessem os bens, que entre eles depositou a natureza, quão infelizes seriam todos os outros, que não possuem terras exóticas!" (PAIVA, 1790, p. 52)

O relatório do marquês de Lavradio (1863, p. 470) também é bastante enfático em mostrar como seu governo não mediu esforços para incentivar a cultura de produtos considerados estratégicos de serem desenvolvidos. $\mathrm{O}$ anil, a guaxima (produtora de linho), o cânhamo, a cochonilha, dentre outros fo- 
ram altamente estimulados a serem plantados e vendidos ao Reino. $\mathrm{O}$ anil, por exemplo, quando entregue pelos lavradores aos armazéns da Provedoria da Fazenda era pago à vista, os comerciantes vinham comprando "avultadíssimas porções, além do que alguns lavradores tem feito carregar por sua própria conta". Todas as culturas contavam com o apoio da Academia Científica que não deixava de divulgar seus estudos a respeito de cada uma delas. Assim ambos, produtos agrícolas e plantas medicinais, mereciam destacado cuidado e análise minuciosa.

A Academia Médico, Cirúrgica, Botânica, Farmacêutica do Rio de Janeiro, nossa Academia Científica, ${ }^{7}$ funcionou até a volta, em 1779, do marquês do Lavradio para a metrópole. Embora curta tenha sido sua existência, importante foram seus feitos e a formação propiciada aos seus sócios. Primeira academia de ciências em território português, não ocorreu por acaso. $\mathrm{O}$ Brasil era a mais rica colônia; aqui os acadêmicos valiam-se das observações diretas que a natureza propiciava (pois como dizia Garcia da Orta - eu vi ). Isto porque as riquezas naturais a explorar encontravam-se a altura dos olhos e os homens de ciência punham-se a decodificá-la e experimentá-la in loco, sem precisar apelar para plantas desidratadas que a muito custo lhes chegassem às mãos, muitas vezes já danificadas.

Ademais as ligações estabelecidas entre os Henriques de Paiva, Ribeiro Sanches e a Academia de Ciências da Suécia, proporcionaram vínculos e discussões entre os acadêmicos que extrapolavam ao controle metropolitano. Vale ressaltar que as contendas e ações empreendidas pela Academia do Rio de Janeiro ocorriam concomitantemente com a reforma dos Estatutos da Universidade de Coimbra, considerada o marco inicial dos estudos de história natural no reino.

Outrossim o desenvolvimento da prática agrícola e o incremento do estudo das plantas medicinais brasileiras, via Academia Científica tornou-as conhecidas, úteis e rentáveis no mundo europeu.

Em clássico estudo, Maria Odila da Silva Dias (1968, p.131-132) registra traços da ilustração dentre nós, principalmente a partir da última década

7 Mencionam a Academia Científica do Rio de Janeiro: Francisco Adolfo de Varnhagen (História geral do Brasil, tomo IV); Lycurgo Santos Filho (História geral da medicina brasileira, vol. 1); Fernando de Azevedo (A cultura brasileira), Maria Odila da Silva Dias ("Aspectos da ilustração no Brasil"); Fernando Novais (Portugal e Brasil na crise do antigo sistema colonial 1777-1808); Bella Herson ("Cristãos-novos e seus descendentes na medicina brasileira"); Maria Rachel Froés da Fonseca ("A única ciência é a pátria: o discurso científico na construção do Brasil e do México (1770-1815); dentre outros. 
dos anos 1790, quando destaca os ilustrados brasílicos, salientando suas atuações ao participarem de forma intensa na política ultramarina portuguesa ou nas reformas empreendidas: vide Universidade de Coimbra, na qual os brasileiros também se projetaram como professores. No entanto, a atuação dos acadêmicos no Rio de Janeiro no período de 1772-1779 são a prova de que a ilustração já havia chegado na colônia do Brasil. Ao proporem a promoção da agricultura pela exploração da rica flora colonial, ganhando relevo os produtos descritos como cultiváveis, faziam da academia espaço de ensino e pesquisa aplicada que permitissem retornar à metrópole, via produtos agrícolas, os lucros que a mineração vinha retirando. Propostas essas que se tornaram política prioritária da coroa quando no governo de D. Maria I se organizam explorações de cunho naturalístico: vide Viagem filosófica de Alexandre Rodrigues Ferreira, por exemplo.

Muitos desses atuantes ilustrados continuariam suas trajetórias científicas ao participar da Sociedade Literária do Rio de Janeiro, academia que sucedeu a Científica e que manteve dentre sua pauta de atuação, os estudos da natureza. Também na Viradeira, homens de ciência passam a atuar em escolas institucionalizadas, valendo-se com certeza do aprendizado nessas academias.

É o caso de Manuel Joaquim Henriques de Paiva, inicialmente acadêmico no Rio de Janeiro, que de volta a Portugal forma-se médico e professor. Em Lisboa, publica Elementos de química e farmácia, em 1783, pela Academia Real das Ciências, pois participava como sócio da instituição, apresentando memórias relativas ao Brasil, fossem elas de sua própria lavra ou de seu irmão Henriques Ferreira que viera a falecer em 1780. Em 1785 vem à luz sua Farmacopéia lisbonense ou coleção dos símplices, preparações e composições mais eficazes, e de maior uso (1802). Foi também nomeado médico da Real Câmara, deputado ordinário da Real Junta de Proto-Medicato, censor na Mesa do Desembargo do Paço, além de ter sido honrado com a comenda de cavaleiro da ordem de Cristo (CARVAlHo, 1939, p. 24).

Henriques de Paiva, afora outras aulas noticiadas na Gazeta de Lisboa em anos posteriores, lecionou até 1807 no Laboratório da Casa da Moeda, onde funcionava a nova cadeira de Farmácia como anexo da Faculdade de Filosofia de Coimbra (CARVAlHo, 1939, p. 24), procedimento muito semelhante ao ocorrido posteriormente na Bahia, quando lá foi lente desta disciplina.

Inocêncio Francisco da Silva (1862, p. 12-18), no seu Dicionário bibliográfico português, aborda um sem número de obras de Manoel Joaquim dentre originais, traduzidas e emendadas, afora as notícias publicadas na im- 
prensa diária ou científica, conjunto este composto principalmente por temas atinentes à medicina, farmácia química e história natural. ${ }^{8}$

Porém, quando as tropas de Napoleão chefiadas por Junot chegam a Lisboa, as autoridades lusitanas acreditaram na organização de apoio a Napoleão a partir da Botica do Azevedo. Manoel Joaquim Henriques de Paiva "foi preso, exautorado de suas honras, condenado a perder seus bens, levou açoutes na via pública e sofreu pena de degredo" para o Brasil por ter comentado, num dos tantos colóquios que aconteciam na botica, que os portugueses não conseguiriam resistir às tropas francesas (FORJAZ, 1961, p. 5-6).

Nessa volta ao Brasil, o médico-boticário fica então sediado na Bahia, onde será perdoado de sua pena em 1816. Conforme ordem régia assim expedida:

Tendo sua Alteza Real o Príncipe Regente meu senhor em resolução de 9 de dezembro passado tomada sobre consulta da Mesa do Desembargo do Paço de Lisboa consultado por efeitos de sua real piedade a Manoel Joaquim Henriques de Paiva o degredo de dez anos para Moçambique pelo tempo que ele se tem conservado preso nesta cidade. É o mesmo senhor servido que sem embargo de não se terem ainda expedido por aquele Tribunal os competentes despachos, que ele não deixará de os mandar solicitar para todo tempo lhe servirem de título, V. Ex. o mande já por em sua liberdade. O que participo a V. Ex. para que assim se execute (APEB, Ordens Régias, 1816, doc.16).

Em 1819, Henriques de Paiva, representado pelo governador da Capitania da Bahia, conde da Palma, dirige-se ao rei para solicitar permissão para ficar na Bahia, lecionando a cadeira de Farmácia que regia em Lisboa. Atendido em seu pedido por meio da Carta Régia de 29 de novembro do corrente, ele passaria a ensinar não só os alunos do curso Médico-cirúrgico como também outras pessoas que quisessem instruir-se nos estudos farmacêuticos, como mencionava a ordem do rei (APEB, Ordens Régias, 1819, doc. 339).

Como relata Gonçalo Moniz (1923, p. 26-27), essa cadeira não fazia parte do Colégio Médico-Cirúrgico, nem pertencia “o proprietário dela ao

8 No Catálogo de livros e editores publicado em Lisboa em 1790, constam nada menos do que 47 livros, entre compostos, traduzidos ou mandados imprimir por Henriques de Paiva (ANTT/ RMC, caixa 494, n. 9) 
respectivo corpo docente". Mais tarde, após a independência e atendendo pedido da congregação do Colégio, D. Pedro I incorporou-a ao curso. E a espaçosa botica do convento de Santa Teresa foi cedida para que aí Henriques de Paiva ministrasse suas lições, transferindo a sua cátedra e os utensílios que possuía adquiridos a sua custa (PEREIRA, 1923, p. 20). Tornava-se assim o primeiro professor da cadeira de farmácia no curso Médico-cirúrgico (1813), primeiro curso superior, criado no Brasil então com a denominação de Escola de Cirurgia da Bahia (1808), que em 1832 passaria a chamar-se Faculdade de Medicina (Memorial da medicina, s.d.).

Também desde a independência o professor adotara a nacionalidade brasileira e assim faleceu na Bahia em 10 de março de 1829, de onde ainda viria publicar algumas memórias, dentre as quais: "Memória sobre a excelência, virtudes e uso medicinal da verdadeira Água de Inglaterra..." (Bahia, 1815); "Memória sobre a encefalocele" (Bahia, 1815) e "Dicionário de Botânica" (Bahia, 1819), dentre outros (sANTOS, 1854, p. 121; TORRES, 1946, p. 120).

Como salientava Joaquim José de Ataíde (1882, p. 69), presidente da Sociedade Literária do Rio de Janeiro, em discurso proferido em 1787, "a constante experiência de muitos séculos tem mostrado, que é do seio das academias e sociedades literárias, que tem saído os maiores progressos e resultado o maior adiantamento das ciências; sendo estas uns dos mais inestimáveis tesouros dos reinos e dos impérios (...)" .

E podemos emendar, o iluminismo ao pregar a crença no poder da educação, fazia desses homens cientistas e dos espaços das academias, escolas de homens de ciência.

\section{REFERÊNCIAS}

ACADEMIA DE CIÊNCIAS DE LISBOA. Manuscrito Azul, n. 374. Memória n. 30. História do descobrimento da cochonilha no Brasil, da sua natureza, geração, criação, colheitas e utilidades. Século XVIII.

ARQUIVO NACIONAL DA TORRE DO TOMBO. Real Mesa Censória (RMC), caixa 494, documento 9 .

ARQUIVO PÚBLICO DO ESTADO DA BAHIA. Seção Colonial e Provincial. Coleção de ordens régias. Maço 120, 1819, documento 339.

cumento11.

. Seção Colonial e Provincial. Coleção de ordens régias. Maço 118, 1816, do- 
AZEVEDO, F. de. A cultura brasileira. São Paulo: Melhoramentos, 1964.

BOTO, C. Iluminismo e educação em Portugal: o legado do século XVIII ao XIX. Revista da Faculdade de Educação (USP), v. 22, n. 1, p. 169-191, 1996.

CARDOSO, W.; NOVAIS, F.; D’AMBRÓSIO, U. Para uma história das ciências no Brasil colonial. Revista Brasileira de História da Ciência, n. 1, p. 13-17, jan./jun. 1985.

CARVALHO, A. As academias científicas do Brasil no Século XVIII. Memórias da Academia de Ciências de Lisboa. Lisboa: Classe de Ciências, 1939. Tomo 2.

CARVALHO, R. A actividade pedagógica da Academia de Ciências de Lisboa nos séculos XVIII e XIX. Lisboa: Publicações do II Centenário da Academia das Ciências de Lisboa, 1981.

CORREIA DA SERRA. Memórias econômicas para o adiantamento da agricultura, das artes, e da indústria em Portugal e suas conquistas. Lisboa: Academia de Ciências de Lisboa, 1789. Tomo I.

DIAS, M. S. Aspectos da ilustração no Brasil. Revista do Instituto Histórico e Geográfico Brasileiro, v. 278, 1968.

FONSECA, M. R. F. A única ciência é a pátria: o discurso científico na construção do Brasil e do México (1770-1815). São Paulo, 1996. Tese (Doutorado) - Departamento de História, Faculdade de Filosofia, Letras e Ciências Humanas.

FORJAZ, P. O segredo da esfinge: uma botica de Lisboa de 1775. Separata de: Anais Azevedos , v. 13, n. 2-3, 1961.

GOVERNO DO ESTADO DA BAHIA. Memorial da medicina: a história da medicina brasileira. Salvador: [s.n.], s.d. Informe.

HERSON, B. Cristãos-novos e seus descendentes na medicina brasileira. São Paulo, 1988. Tese (Doutorado) - Departamento de História, Faculdade de Filosofia, Letras e Ciências Humanas, Universidade de São Paulo.

JANEIRA, A. L. A ciência nas academias portuguesas (século XVIII). Revista da $S B P C$, v. 5, p. 15-21, 1991.

LAVRADIO, M. Cartas do Rio de Janeiro. Rio de Janeiro: Instituto Estadual do Livro, 1978.

. Relatório do Marquês de Lavradio, vice-rei do Rio de Janeiro entregando o governo a Luís de Vasconcellos e Sousa, que o sucedeu. Revista do Instituto Histórico e Geográfico Brasileiro, 1863. Tomo 4.

LEMOS, M. Ribeiro Sanches, a sua vida e a sua obra. Porto: Tavares Martins, 1911. . Estudos de história da medicina peninsular. Porto: Tipografia da Enciclopédia Portuguesa, 1916. 
LENOBLE, R. História da idéia de natureza. Lisboa: Ed. 70, s.d.

MARQUES, V. R. B. Natureza em boiões: medicinas e boticários no Brasil setecentista. Campinas: Unicamp, 1999.

MAXWELL, K. Marquês de Pombal: paradoxo do Iluminismo. São Paulo: Paz e Terra, 1996.

MONIZ, G. A medicina e sua evolução na Bahia. Bahia: Imprensa Oficial, 1923.

MUNTEAL, F. O. Domenico Vandelli no anfiteatro da natureza: a cultura científica do reformismo ilustrado português na crise do antigo sistema colonial (1779-1808). Rio de Janeiro, 1993. Dissertação (Mestrado) - Departamento de História, Pontifícia Universidade Católica do Rio de Janeiro.

NOVAIS, F. Portugal e Brasil na crise do antigo sistema colonial (1777-1808). São Paulo: Hucitec, 1985.

PAIVA, M. J. H. Farmacopéia lisbonense. Lisboa: Of. de João Procópio Correa da Silva, 1802.

. Memórias de história natural, de química, de agricultura, artes, e medicina. Lisboa: [s.n.], 1790. Tomo 1.

PEREIRA, A. P. Memória sobre a medicina na Bahia. Bahia: Imprensa Oficial, 1923.

SAMPAIO, F. História dos reinos vegetal, animal, e mineral do Brasil, pertencentes à medicina. Anais da Biblioteca Nacional, v. 89, 1969.

SANCHES, A. R. Obras: método para aprender e estudar a medicina. Coimbra: Universidade de Coimbra, 1950.

. Considerações sobre o governo do Brasil desde o seu estabelecimento até o presente tempo (1777). In: LEMOS, M. Ribeiro Sanches, a sua vida e sua obra. Porto: Tavares Martins, 1911.

SANTOS, F. L. História geral da medicina brasileira. São Paulo: Hucitec/Edusp, 1991. v. 1.

SANTOS, M. A. Memórias históricas da Faculdade de Medicina da Bahia. [s.1.: s.n.], 1854.

SILVA, M. B. N. (Coord.). Dicionário da história da colonização portuguesa no Brasil. Lisboa: Verbo, 1994.

SUMÁRIO da história do descobrimento da cochonilha no Brasil, e das observações, que sobre ela fez no Rio de Janeiro o Dr. José Henriques Ferreira, médico do vice-rei o marques de Lavradio. O Patriota, n. 1, 1814. (terceira subscrição).

TORRES, O. Esboço histórico dos acontecimentos mais importantes da vida da Faculdade de Medicina da Bahia (1808-1946). Bahia: Imprensa Vitória, 1946. 
VAINFAS, R. (Dir.). Dicionário do Brasil colonial (1500-1808). Rio de Janeiro: Objetiva, 2000.

VARnHAGEN, F. A. História geral do Brasil. São Paulo: Melhoramentos, 1962. Tomo 3-4.

VERNEY, L. A. Verdadeiro método de estudar. Prefácio e notas de Joaquim Ferreira. Porto: Domingos Barreira, s.d.

WEHLING, A. O fomentismo português no final do século XVIII: doutrinas, mecanismos, exemplificações. Revista do Instituto Histórico e Geográfico Brasileiro, v. 316, 1977.

Texto recebido em 23 out. 2004 Texto aprovado em 27 nov. 2004 